Abstracted/indexed in Academic Search Complete, Asia Journals Online, Bangladesh Journals Online, Biological Abstracts, BIOSIS Previews, CAB

Abstracts, Current Abstracts, Directory of Open Access Journals, EMBASE/Excerpta Medica, Google Scholar, HINARI (WHO), International

\title{
Non-invasive positive pressure ventilation offers greater improvement in COPD-related respiratory failure when combined with naloxone
}

\section{Long Zhang, Wei Zhao, Qinfu Xu, Yu-Miao Zhao, Jun-Jie Zhao, Yin-long Ren, Yu-jing Liu, Jing $\mathrm{Li}$ and $\mathrm{Ai}$-Guo $\mathrm{Xu}$}

Department of Respiration and Intensive, The First Affiliated Hospital of Zhengzhou University, Zhengzhou 450 052, Henan Province, China.

\begin{tabular}{|c|c|}
\hline Article Info & \\
\hline Received: & 24 October 2015 \\
\hline Accepted: & 20 February 2016 \\
\hline Available Online: & 21 March 2016 \\
\hline DOI: $10.3329 /$ bjp.v & $1 \mathrm{i} 2.25469$ \\
\hline $\begin{array}{l}\text { Cite this article: } \\
\text { Zhang L, Zhao V } \\
\text { Zhao J, Xu A. No } \\
\text { pressure ventilati } \\
\text { improvement in C } \\
\text { atory failure wh } \\
\text { naloxone. Bangla } \\
\text { 2016; 11: 359-63. }\end{array}$ & $\begin{array}{l}\text { Xu Q, Zhao Y, } \\
\text {-invasive positive } \\
\text { n offers greater } \\
\text { PD-related respir- } \\
\text { combined with } \\
\text { esh J Pharmacol. }\end{array}$ \\
\hline
\end{tabular}

\begin{abstract}
To improve efficacy of non-invasive positive pressure ventilation (NPPV), this study investigated the combination of NPPV with naloxone in COPD patients with respiratory failure. One hundred four patients with COPD-related respiratory failure were enrolled prospectively and randomly divided into a control group treated with NPPV alone $(\mathrm{n}=52)$ and an observation group treated with NPPV combined with $4.0 \mathrm{mg}$ naloxone by continuous infusion (n $=52$ ). At 3 and 5 days after the start of treatment, the respiratory mechanics, pulmonary function, and oxygen metabolism parameters were significantly improved in the NPPV + naloxone group compared to the NPPV alone group $(\mathrm{p}<0.05)$. Further, the improvements in the NPPV plus naloxone group were greater at day 5 than at day $3(p<0.05)$. These findings indicate that noninvasive positive pressure ventilation combined with naloxone can more effectively improve respiratory mechanics, pulmonary function and oxygen metabolism of COPD patients with respiratory failure than NPPV alone, offering a new treatment approach.
\end{abstract}

\section{Introduction}

Chronic obstructive pulmonary disease (COPD) refers to chronic bronchitis and emphysema characterized by airflow obstruction. This clinically common chronic respiratory disease can further develop into pulmonary heart disease and respiratory failure (Paap et al., 2014). COPD causes high global rates of morbidity and mortality, seriously affecting the quality of life of patients around the world (Pauwels et al., 2014). During the development of disease, COPD patients can present with abnormalities in respiratory mechanics, lung function and oxygen metabolism parameters, with an overall reduced oxygen supply (Casaburi and ZuWallack, 2009). These indexes are useful for evaluating the development of COPD, and overall improvements in each of them is an important objective for treatment of patients with respiratory failure due to COPD.
The standard treatment for COPD comprises life style changes and medications that temporarily relieve breathing difficulties; treatment of acute respiratory failure due to COPD typically requires mechanical ventilation (Pauwels et al., 2014). However, a more recent approach, non-invasive positive pressure ventilation (NPPV) is gaining traction as an effective and useful treatment option for COPD-related respiratory failure. NPPV refers to positive pressure ventilation that is not delivered via endotracheal or tracheostomy tube. In addition to treating acute respiratory failure due to COPD, with a success rate of 80-85\% (Köhnlein et al., 2014; Elliott 2002; Wei et al., 2012; Halpin and Miravitlles, 2006), NPPV can reduce pain and treatment costs compared with conventional mechanical ventilation via an artificial airway (Briones Claudett et al., 2013). Indeed, it can effectively prevent and treat a blockage in the airway and proactively improve the independent ventilation function and diffusion capacity (Potts 2009; Schettino et al., 2008). 
Therefore, NPPV now plays a proactive role in the improvement of acute respiratory failure in patients. Room for improvement remains, however, for the use of NPPV in treating lung function and oxygen metabolism. Thus, approaches that can augment the effectiveness of NPPV must be found to achieve better patient outcomes.

Naloxone is an opioid receptor antagonist with a chemical structure similar to that of morphine, but with a great affinity for opioid receptor. This affinity can prevent morphine-like substances from binding to opioid receptors. Additionally, it can increase the respiratory rate of patients who present with respiratory depression due to acute poisoning, effectively reversing the respiratory depression and playing a role in exciting the respiratory center, causing sedation, and raising the blood pressure (Fakiris et al., 2009; Yoshitake et al., 2012; Ricardi et al., 2010). Clinically, naloxone can improve respiration, pulmonary ventilation, and gas exchange, as well as improving flow in the airway, thereby treating both symptoms and root causes (Tashkin, 2010; Decramer et al., 2009).

We hypothesized that the actions of naloxone may serve to augment the effectiveness of NPPV when the treatments were combined for patients with COPDrelated respiratory failure. Therefore, in this study we observed the effect of NPPV combined with naloxone on the respiratory mechanics, lung functions, and oxygen metabolism of patients with respiratory failure due to COPD. The results suggest a potential new treatment approach for COPD-related acute respiratory failure.

\section{Materials and Methods}

\section{Participants}

This prospective study included 104 patients with respiratory failure due to COPD, who were randomly divided into an observation group of 52 cases who were treated with NPPV combined with naloxone and a control group of 52 cases who were treated with NPPV alone. Patients were treated in our hospital between September 2012 and December 2014.

In the NPPV + naloxone group, 31 cases (59.6\%) were males and 21 cases $(40.4 \%)$ were females. The mean patient age was $64.1 \pm 7.1$ years and the mean disease duration was $12.1 \pm 1.5$ years (ranging from 3.95 to 20.10 years). Twenty-eight cases $(53.9 \%)$ had moderate respiratory failure (PaCO2 from 50 to $69 \mathrm{mmHg}$ ) and 24 cases $(46.2 \%)$ had severe respiratory failure $(\mathrm{PaCO} 2 \geq 70$ $\mathrm{mmHg})$.

In the NPPV alone group, 30 cases (57.7\%) were males and 22 cases $(42.3 \%)$ were females. The mean patient age was $64.1 \pm 7.0$ years and the mean disease duration was $12.0 \pm 1.5$ years (ranging from 4.1 to 20.0 years). Twenty-nine cases $(55.8 \%)$ had moderate respiratory failure and 23 cases $(44.2 \%)$ had severe respiratory failure. The differences between both groups regarding their age, sex and disease duration as well as severity and duration of acute exacerbation of respiratory failure were not statistically significant (each $\mathrm{P}$ value $>0.05$ ); thus the groups were comparable.

\section{Treatment methods}

The NPPV alone group received additional NPPV based on the conventional treatment, which mainly involved oxygen inhalation, relieving obstructive spasms, fighting inflammation and infection, regulating electrolyte balance, and maintaining nutrition. NPPV was performed using ZN17-SC300 multifunctional ventilators (Far East Technology, Beijing, China) at an initial positive end-expiratory pressure of 2-4 $\mathrm{cmH}_{2} \mathrm{O}$ and a respiratory rate of 16 beats per minute, which were adjusted according to patient condition during the noninvasive mechanical ventilation. The NPPV + naloxone group received NPPV combined with naloxone based on the conventional treatment, in which each patient received a 24 hours continuous intravenous injection of $4.0 \mathrm{mg}$ naloxone. Both groups received treatment for 5 consecutive days. At 3 and 5 days after the start of treatment, their respiratory mechanics, lung function, and oxygen metabolism parameters were collected and compared with those before treatment.

\section{Monitoring indexes}

Bicore CP-100 (USA) was used to measure the respiratory mechanics parameters including peak inspiratory pressure (PIP), plateau pressure (PP), pressure mean $(\mathrm{Pm})$, minute ventilation (VE) and airway resistance (R). Lung function parameters were expressed as various indexes of pulmonary gas exchange and pulmonary ventilation. The diffusing capacity of the lungs for carbon monoxide (DLCo), maximal inspiratory mouth pressure (PImax), maximal expiratory mouth pressure (PEmax), and oxygen partial pressure $\left(\mathrm{PO}_{2}\right)$ at rest were determined. Forced expiratory volume in 1 second (FEV1), peak expiratory flow at 25\% (PEF25), peak expiratory flow at 50\% (PEF50) and total lung capacity (TLC) were measured using a Vmax Encore 229/22D spirometer (Sensormedics). The oxygen metabolism parameters comprised the arterial oxygen content $\left(\mathrm{CaO}_{2}\right)$, mixed venous oxygen saturation $\left(\mathrm{SvO}_{2}\right)$, oxygen consumption $\left(\mathrm{VO}_{2}\right)$, and oxygen extraction rate $\left(\mathrm{ERO}_{2}\right)$, all of which were detected using a GEM Premier 3000 blood gas analyzer (USA).

\section{Statistical analysis}

In this study, double data entry was performed using Epi Data version 3.1 to create a data bank, and logic 
checks were performed. SAS 9.2 (SAS Institute, USA) was used to analyze the data. Statistical methods included the chi-squared test and t-test. $p<0.05$ was considered to indicate a difference was statistically significant.

\section{Results}

Pre- and post-treatment respiratory mechanics parameters in patients with COPD-related respiratory failure.

Before treatment, no differences were observed between treatment groups regarding PIP, PP, Pm, VE, or R (each $p$ value $>0.05$, Table I). However, at 3 and 5 days after treatment, each of these parameters was significantly lower in the observation group than in the control group (each $p$ value $<0.05$, Table I). Further, within the group of patients treated with NPPV + naloxone, each of the measures was significantly lower at 5 days after treatment than at 3 days after treatment (each $p$ value $<0.05$, Table I).

Pulmonary gas exchange parameters pre- and posttreatment in patients with COPD-related respiratory failure.
Before treatment, no differences were observed between groups regarding DLCO, PImax, $\mathrm{PEmax}$, or $\mathrm{PO}_{2}$ (each $\mathrm{P}$ value $>0.05$ ) (Table II). However, at 3 and 5 days after the start of treatment, each parameter was significantly higher in the observation group than in the control group (each $p$ value $<0.05$ ). Further, within the group of patients treated with NPPV + naloxone, each of the measures was significantly higher at 5 days after treatment than at 3 days after treatment (each $P$ value $<0.05)$.

Pulmonary ventilation function before and after treatment in patients with COPD-related respiratory failure.

Before treatment, no differences were observed between groups regarding FEV1, PEF25, PEF50, or TLC were (each $\mathrm{p}$ value $>0.05$ ) (Table III). However, at 3 and 5 days after treatment, all parameters were significantly higher in the NPPV + naloxone group than in the NPPV alone group (each $\mathrm{P}$ value $<0.05$ ). In addition, within the group of patients treated with NPPV + naloxone, the parameters were significantly higher 5 days after treatment than 3 days after treatment (each $p$ value

\section{Table I}

The comparison of respiratory mechanics between the NPPV + naloxone and NPPV alone

\begin{tabular}{|llccccc|}
\hline Groups & & \multicolumn{1}{c}{$\begin{array}{c}\mathrm{PIP} \\
\left(\mathrm{cmH}_{2} \mathrm{O}\right)\end{array}$} & $\begin{array}{c}\mathrm{PP} \\
\left(\mathrm{cmH}_{2} \mathrm{O}\right)\end{array}$ & $\begin{array}{c}\mathrm{Pm} \\
\left(\mathrm{cmH}_{2} \mathrm{O}\right)\end{array}$ & $\begin{array}{c}\mathrm{VE} \\
(\mathrm{L} / \mathrm{min})\end{array}$ & $\begin{array}{c}\mathrm{R} \\
{\left[\mathrm{cmH}_{2} \mathrm{O} /\right.} \\
\left(\mathrm{L}^{*} \mathrm{~s}\right)\end{array}$ \\
\hline $\begin{array}{l}\text { NPPV alone } \\
(\mathrm{n}=52)\end{array}$ & Before treatment & $39.1 \pm 4.6$ & $29.0 \pm 3.6$ & $20.0 \pm 3.4$ & $8.3 \pm 1.3$ & $41.0 \pm 3.5$ \\
& 3 days after the start of treatment & $35.9 \pm 3.8$ & $26.1 \pm 3.2$ & $18.1 \pm 3.0$ & $8.0 \pm 1.2$ & $39.0 \pm 3.2$ \\
& 5 days after the start of treatment & $31.1 \pm 3.3$ & $23.1 \pm 2.6$ & $15.9 \pm 2.8$ & $7.7 \pm 1.0$ & $36.1 \pm 3.1$ \\
$\begin{array}{l}\text { NPPV + nalox- } \\
\text { one }(\mathrm{n}=52)\end{array}$ & Before treatment & $39.1 \pm 4.6$ & $29.0 \pm 3.6$ & $20.0 \pm 3.4$ & $8.3 \pm 1.3$ & $41.0 \pm 3.5$ \\
& 3 days after the start of treatment & $32.0 \pm 4.1^{\mathrm{a}}$ & $22.0 \pm 2.6^{\mathrm{a}}$ & $15.4 \pm 2.8^{\mathrm{a}}$ & $7.3 \pm 1.0^{\mathrm{a}}$ & $34.8 \pm 3.1^{\mathrm{a}}$ \\
& 5 days after the start of treatment & $28.1 \pm 3.0^{\mathrm{ab}}$ & $18.1 \pm 2.1^{\mathrm{ab}}$ & $12.9 \pm 2.1^{\mathrm{ab}}$ & $67.0 \pm 0.9^{\mathrm{ab}}$ & $30.0 \pm 3.0^{\mathrm{ab}}$ \\
\hline
\end{tabular}

Data are mean $\pm \mathrm{SD}$; ${ }^{a} \mathrm{p}<0.05$, compared with NPPV alone; ${ }^{\mathrm{b}} \mathrm{p}<0.05$, compared with 3 days after the start of treatment

\section{Table II}

Pulmonary gas exchange measurements in patients with COPD-related respiratory failure before and after treatment with NPPV alone or in combination with naloxone

\begin{tabular}{|llrrrc|}
\hline Group & & $\begin{array}{c}\text { DLCO } \\
(\mathrm{mL} / \mathrm{min} * \mathrm{kPa})\end{array}$ & $\begin{array}{c}\text { PImax } \\
(\%)\end{array}$ & $\begin{array}{c}\text { PEmax } \\
(\%)\end{array}$ & $\begin{array}{c}\mathrm{PO}_{2} \\
(\mathrm{mmHg})\end{array}$ \\
\hline $\begin{array}{l}\text { NPPV alone } \\
(\mathrm{n}=52)\end{array}$ & Before treatment & $152.1 \pm 14.0$ & $57.1 \pm 7.1$ & $31.8 \pm 3.0$ & $60.1 \pm 7.1$ \\
& 3 days after the start of treatment & $173.3 \pm 14.8$ & $67.6 \pm 8.6$ & $38.2 \pm 3.3$ & $64.1 \pm 7.3$ \\
& 5 days after the start of treatment & $191.2 \pm 15.5$ & $78.5 \pm 9.2$ & $42.4 \pm 3.5$ & $72.2 \pm 7.5$ \\
$\begin{array}{l}\text { NPPV + naloxone } \\
(\mathrm{n}=52)\end{array}$ & Before treatment & $152.1 \pm 14.1$ & $57.1 \pm 7.2$ & $31.9 \pm 3.0$ & $60.0 \pm 7.1$ \\
& 3 days after the start of treatment & $202.9 \pm 15.6^{\mathrm{a}}$ & $81.5 \pm 9.6^{\mathrm{a}}$ & $46.3 \pm 4.0^{\mathrm{a}}$ & $73.1 \pm 7.3^{\mathrm{a}}$ \\
& 5 days after the start of treatment & $214.4 \pm 18.1^{\mathrm{ab}}$ & $89.3 \pm 10.0^{\mathrm{ab}}$ & $51.1 \pm 4.1^{\mathrm{ab}}$ & $78.1 \pm 7.7^{\mathrm{ab}}$ \\
\hline
\end{tabular}

Data are mean $\pm \mathrm{SD} ;{ }^{\mathrm{a}} \mathrm{p}<0.05$, compared with control group; ${ }^{\mathrm{b}} \mathrm{p}<0.05$, compared with 3 days after the start of treatment 
Table III

Pulmonary function measurements before and after treatment with NPPV or NPPV plus naloxone

\begin{tabular}{|c|c|c|c|c|c|}
\hline Group & & FEV1 (L) & PEF25 (L/s) & PEF50 (L/s) & TLC (L) \\
\hline \multirow[t]{3}{*}{ NPPV alone $(n=52)$} & Before treatment & $1.3 \pm 0.2$ & $2.0 \pm 0.4$ & $1.0 \pm 0.2$ & $1.4 \pm 0.2$ \\
\hline & 3 days after the start of treatment & $1.8 \pm 0.2$ & $2.4 \pm 0.4$ & $1.1 \pm 0.2$ & $1.9 \pm 0.2$ \\
\hline & 5 days after the start of treatment & $2.1 \pm 0.2$ & $2.6 \pm 0.4$ & $1.3 \pm 0.2$ & $2.4 \pm 0.2$ \\
\hline \multirow[t]{3}{*}{ NPPV + naloxone $(n=52)$} & Before treatment & $1.33 \pm 0.2$ & $2.0 \pm 0.3$ & $1.1 \pm 0.2$ & $1.4 \pm 0.2$ \\
\hline & 3 days after the start of treatment & $2.4 \pm 0.2^{\mathrm{a}}$ & $3.3 \pm 0.4^{\mathrm{a}}$ & $1.5 \pm 0.2^{\mathrm{a}}$ & $3.2 \pm 0.3^{a}$ \\
\hline & 5 days after the start of treatment & $2.7 \pm 0.2^{\mathrm{ab}}$ & $3.8 \pm 0.5^{\mathrm{ab}}$ & $1.8 \pm 0.3^{\mathrm{ab}}$ & $3.9 \pm 0.3^{\mathrm{ab}}$ \\
\hline
\end{tabular}

Data are mean $\pm \mathrm{SD}$; ${ }^{a} \mathrm{p}<0.05$, compared with NPPV alone; ${ }^{\mathrm{b}} \mathrm{p}<0.05$, compared with 3 days after the start of treatment

Table IV

Oxygen metabolism measurements before and after treatment with NPPV alone or in combination with na-

\begin{tabular}{|c|c|c|c|c|c|}
\hline Group & & $\mathrm{CaO}_{2}(\mathrm{~mL} / \mathrm{L})$ & $\mathrm{SvO}_{2}(\%)$ & $\begin{array}{r}\mathrm{VO}_{2}(\mathrm{~mL} / \\
\left.\mathrm{min}^{*} \mathrm{~m}^{2}\right)\end{array}$ & $\mathrm{ERO}_{2}(\%)$ \\
\hline \multirow[t]{3}{*}{ NPPV alone $(\mathrm{n}=52)$} & Before treatment & $103.9 \pm 6.5$ & $60.4 \pm 6.0$ & $149.0 \pm 7.1$ & $31.8 \pm 5.1$ \\
\hline & 3 days after the start of treatment & $124.2 \pm 7.8$ & $63.8 \pm 6.1$ & $145.0 \pm 6.8$ & $29.0 \pm 4.7$ \\
\hline & 5 days after the start of treatment & $143.7 \pm 8.6$ & $67.8 \pm 6.4$ & $138.0 \pm 6.6$ & $25.4 \pm 4.2$ \\
\hline \multirow[t]{3}{*}{$\mathrm{NPPV}+$ naloxone $(\mathrm{n}=52)$} & Before treatment & $104.0 \pm 6.5$ & $60.4 \pm 6.1$ & $149.1 \pm 7.2$ & $31.8 \pm 5.1$ \\
\hline & 3 days after the start of treatment & $151.3 \pm 9.0^{a}$ & $69.1 \pm 6.5^{a}$ & $133.2 \pm 6.3^{a}$ & $25.9 \pm 4.5^{\mathrm{a}}$ \\
\hline & 5 days after the start of treatment & $170.1 \pm 9.4^{\mathrm{ab}}$ & $73.0 \pm 6.6^{\mathrm{ab}}$ & $122.9 \pm 5.7 \mathrm{ab}$ & $22.8 \pm 4.1^{\mathrm{ab}}$ \\
\hline
\end{tabular}

Data are mean $\pm \mathrm{SD}$; ${ }^{a} \mathrm{p}<0.05$, compared with NPPV alone; ${ }^{\mathrm{b}} \mathrm{p}<0.05$, compared with 3 days after the start of treatment

$<0.05)$.

Oxygen metabolism parameters before and after treatment of patients with COPD-related respiratory failure.

Before treatment, no differences were observed between groups regarding $\mathrm{CaO}_{2}, \mathrm{SvO}_{2}, \mathrm{VO}_{2}$, or $\mathrm{ERO}_{2}$ (each $\mathrm{p}$ value >0.05) (Table IV). However, at 3 and 5 days after treatment, both $\mathrm{VO}_{2}$ and $\mathrm{ERO}_{2}$ were significantly lower in the NPPV + naloxone group than in the NPPV alone group, while both $\mathrm{CaO}_{2}$ and $\mathrm{SvO}_{2}$ were significantly higher in the NPPV + naloxone group than in the NPPV alone group (each $\mathrm{p}$ value $<0.05$ ). In addition, within the NPPV + naloxone group, the measurements at day 5 exceeded those at 3 days after treatment (each $P$ value $<0.05)$.

\section{Discussion}

In the present study, a treatment approach combining NPPV with naloxone conferred greater improvement on respiratory mechanics, pulmonary ventilation, pulmonary gas exchange and oxygen metabolism than NPPV alone in patients with respiratory failure due to COPD. The indicators of respiratory health were measured before and after treatment with NPPV alone or in combination with naloxone, an opioid receptor antagonist that alleviates respiratory distress. Baseline measurements demonstrated that the random assignment of patients produced two treatment groups with equivalent respiratory disease. The respiratory indexes improved with treatment with NPPV alone, but improvement was augmented by the combination of NPPV and naloxone. Indeed, significant improvements were seen in the combination group over the control group 3 days after treatment. Further, the improvements seen after 3 days in the combination group were even greater 5 days after treatment. Thus, treatment with NPPV combined with naloxone improved patients' respiratory mechanics, pulmonary ventilation, pulmonary gas exchange and oxygen metabolism. An improvement in the overall oxygen supply to the patients also confirmed the effects of the combination approach in improving the patients' general condition.

COPD correlates with an abnormal inflammatory response to noxious gases and particles. Risk factors can be roughly divided into external factors (i.e., environmental factors such as dust, smoking and inhaled chemical substances) and internal factors (i.e., individual factors increasing susceptibility to COPD such as genetic determinants and airway hyperresponsiveness). Uncontrolled COPD can lead to acute 
respiratory failure affecting the respiratory mechanics, pulmonary ventilation, pulmonary gas exchange, and oxygen metabolism. These functions cannot be improved unless the respiratory failure is effectively reversed. Therefore, the reversal of these measurements serves as an important indicator for the improvement of respiratory function.

\section{Conclusion}

NPPV combined with naloxone offers an effective treatment approach for COPD-related acute respiratory failure.

\section{Ethical issue}

The study was carried out in accordance with the guidelines drawn up in the declaration of Helsinki. This study was approved by the ethics committee of the first affiliated hospital of Zhengzhou University and all subjects provided written informed consent.

\section{References}

Briones Claudett KH, Briones Claudett M, Chung Sang Wong M, Nuques Martinez A, Soto Espinoza R, Montalvo M, Esquinas Rodriguez A, Gonzalez Diaz G, Grunauer Andrade M. Noninvasive mechanical ventilation with average volume assured pressure support (AVAPS) in patients with chronic obstructive pulmonary disease and hypercapnic encephalopathy. BMC Pulm Med. 2013; 13: 12.

Casaburi R, ZuWallack R. Pulmonary rehabilitation for management of chronic obstructive pulmonary disease. $\mathrm{N}$ Engl J Med. 2009; 360: 1329-35.

Decramer M, Celli B, Kesten S, Lystig T, Mehra S, Tashkin DP, UPLIFT investigators. Effect of tiotropium on outcomes in patients with moderate chronic obstructive pulmonary disease (UPLIFT): A prespecified subgroup analysis of a randomised controlled trial. Lancet. 2009; 374: 1171-78.

Elliott MW. Non-invasive ventilation in acute exacerbations of chronic obstructive pulmonary disease: A new gold standard? Intensive Care Med. 2002; 28: 1691-4.

Fakiris AJ, McGarry RC, Yiannoutsos CT, Papiez L, Williams M, Henderson MA, Timmerman R. Stereotactic body radiation therapy for early-stage non-small-cell lung carcinoma: Four-year results of a prospective phase II study.
Int J Radiat Oncol Biol Phys. 2009; 75, 677-82.

Halpin DG, Miravitlles M. Chronic obstructive pulmonary disease: The disease and its burden to society. Proc Am Thorac Soc. 2006; 3: 619-23.

Köhnlein T, Windisch W, Köhler D, Drabik A, Geiseler J, Hartl S, Karg O, Laier-Groeneveld G, Nava S, Schönhofer B, Schucher B, Wegscheider K, Criée CP, Welte T. Non-invasive positive pressure ventilation for the treatment of severe stable chronic obstructive pulmonary disease: A prospective, multicentre, randomised, controlled clinical trial. Lancet Respir Med. 2014; 2: 698-705.

Paap MC, Bode C, Lenferink LI, Groen LC, Terwee CB, Ahmed $\mathrm{S}$, Eilayyan $\mathrm{O}$, van der Palen J. Identifying key domains of health-related quality of life for patients with chronic obstructive pulmonary disease: The patient perspective. Health Qual Life Outcomes. 2014; 12: 106.

Pauwels RA, Buist AS, Calverley PM, Jenkins CR, Hurd SS. Gold scientific committee. Global strategy for the diagnosis, management, and prevention of chronic obstructive pulmonary disease. Am J Respir Crit Care Med. 2014; 163: 1256-76.

Potts JM. Noninvasive positive pressure ventilation : Effect on mortality in acute cardiogenic pulmonary edema : A pragmatic meta-analysis. Pol Arch Med Wewn. 2009; 119: 349-53.

Ricardi U, Filippi AR, Guarneri A, Giglioli FR, Ciammella P, Franco P, Mantovani C, Borasio P, Scagliotti GV, Ragona R. Stereotactic body radiation therapy for early stage non-small cell lung cancer: Results of a prospective trial. Lung Cancer. 2010; 68: 72-77.

Schettino G, Altobelli N, Kacmarek RM. Noninvasive positivepressure ventilation in acute respiratory failure outside clinical trials: Experience at the Massachusetts General Hospital. Crit Care Med. 2008; 36: 441-47.

Tashkin DP. Impact of tiotropium on the course of moderate to very severe chronic obstructive pulmonary disease: The UPLIFT trial. Expert Rev Respir Med. 2010; 4: 279-89.

Wei M, Ying X, Min D. Clinical study on non-invasive positive pressure ventilation for patients with acute exacerbations chronic obstructive pulmonary diseases with respiratory failure. J Med Res. 2012; 6: 57-59.

Yoshitake T, Nakamura K, Shioyama Y, Sasaki T, Ohga S, Nonoshita T, Terashima K, Asai K, Matsumoto K, Honda H. Stereotactic body radiation therapy for stage I non-small cell lung cancer patients with chronic respiratory insufficiency requiring domiciliary oxygen therapy. Anticancer Res. 2012; 32: $4041-44$. 


\section{Your feedback about this paper}

1. Number of times you have read this paper 0

2. Quality of paper
Excellent
Good
Moderate
Not good

3. Your comments

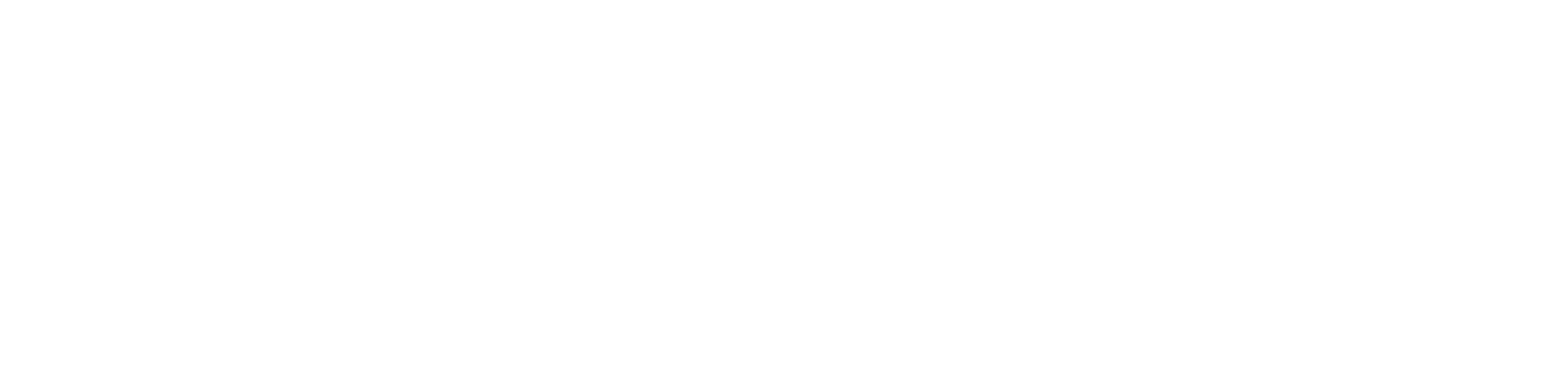

